\title{
HUBUNGAN KECEPATAN, KEPADATAN DAN VOLUME LALU LINTAS DENGAN MODEL GREENSHIELDS (STUDI KASUS JALAN DARUSSALAM LHOKSEUMAWE)
}

\author{
Mukhlis \\ Jurusan Teknik Sipil, Fakultas Teknik, Universitas Malikussaleh \\ Email:muuukhlis@gmail.com
}

\begin{abstract}
Abstrak
Jenis kendaraan lalu lintas yang melintasi Jalan Darussalam Kota Lhokseumawe terdiri dari mobil penumpang, mobil barang, becak dan sepeda motor. Banyaknya kendaraan yang melewati jalan tersebut sangat dipengaruhi oleh banyaknya fasilitas-fasilitas umum yang digunakan oleh masyarakat, seperti pertokoan, mini market, sekolah, pertamina, perkantoran, dan lain-lain. Dalam merepresentasikan hubungan matematis kecepatan, kepadatan dan volume lalu lintas pada Jalan Darussalam Kota Lhokseumawe digunakan model Greenshields. Pengamatan untuk penelitian dilakukan pada haris Senin, Jum'at dan Minggu mulai pukul 07.00 WIB sampai dengan pukul 19.00 WIB. Bentuk matematis hubungan antara Kecepatan dan Kepadatan untuk hari Senin adalah S - D = 42,37 - 0,9611 D, sedangkan untuk hari Jum'at adalah S - D = 22,915 + 0,8513 D dan untuk hari Minggu adalah S - D $=45,5254-0,9922 \mathrm{D}$. Bentuk matematis hubungan antara Volume dan Kepadatan untuk hari Senin adalah V - D = 42,37 D - 0,9611 D², sedangkan pada hari Jum'at adalah $\mathrm{V}-\mathrm{D}=22,915 \mathrm{D}-0,8513 \mathrm{D}^{2}$, dan untuk hari Minggu adalah V - D = 45,5254 D - 0,9922 $\mathrm{D}^{2}$. Bentuk matematis hubungan antara Volume dan Kecepatan untuk hari Senin adalah V - S $=44,0849 \mathrm{~S}$ $0,9611 \mathrm{~S}^{2}$, sedangkan untuk hari Jum'at adalah $\mathrm{V}-\mathrm{S}=-26,9177 \mathrm{~S}+$ $1,1747 \mathrm{~S}^{2}$, dan untuk hari Minggu adalah V - S = 45,8821 S - 1,0078 $\mathrm{S}^{2}$.
\end{abstract}

Kata kunci: Kecepatan, kepadatan, Volume Lalu lintas, Model Greenshields

\section{Pendahuluan}

Jenis kendaraan lalu lintas yang melintasi Jalan Darussalam Kota Lhokseumawe terdiri dari mobil penumpang, mobil barang, becak dan sepeda motor. Banyaknya kendaraan yang melewati jalan tersebut sangat dipengaruhi oleh banyaknya fasilitas-fasilitas umum yang digunakan oleh masyarakat, seperti pertokoan, mini market, sekolah, pertamina, perkantoran, dan lain-lain. Kepadatan kendaraan terjadi pada pagi, siang dan sore hari. Dalam merepresentasikan hubungan matematis kecepatan, kepadatan dan volume lalu lintas pada Jalan Darussalam Kota Lhokseumawe maka dalam penelitian ini akan digunakan model Greenshields. Pengamatan untuk penelitian dilakukan pada haris Senin, Jum'at dan Minggu mulai pukul 07.00 WIB sampai dengan pukul 19.00 WIB. Penelitian ini dilakukan untuk mengetahui hubungan matematis antara kecepatan, kepadatan dan volume lalu lintas pada ruas Jalan Darussalam Lhokseumawe yang semakin hari semakin padat. Kendaraan yang melintasi jalan tersebut umumnya kendaraan yang domisilinya dalam Kota Lhokseumawe dan sekitarnya, sehingga dengan bertambahnya pendapatan masyarakat maka akan meningkat pula penggunaan kendaraan bermotor, baik sepeda motor, becak maupun mobil.

Tujuan dari penelitian adalah untuk merepresentasikan hubungan matematis kecepatan, kepadatan dan volume lalu lintas dengan model Greenshields pada Jalan Darussalam Kota. Hasil penelitian ini dapat menggambarkan hubungan 
matematis kecepatan, kepadatan dan volume lalu lintas dengan model Greenshields dan dapat dijadikan sebagai bahan prediksi untuk peramalan masa yang akan datang. Dapat dijadikan sebagai bahan perbandingan untuk penelitianpenelitian yang serupa pada ruas-ruas jalan yang lain.

Penelitian dilakukan pada Jalan Darussalam Kota Lhokseumawe yaitu membuat hubungan matematis kecepatan, kepadatan dan volume lalu lintas dengan model Greenshields untuk hari Senin, Jum'at dan Minggu dan pengamatan dilakukan mulai pukul 07.00 WIB sampai dengan pukul 19.00 WIB.

\section{Tinjauan Kepustakaan}

\subsection{Kecepatan Lalu Lintas}

Menurut Tamin (2008), kecepatan adalah jarak yang dapat ditempuh oleh sebuah kendaraan dalam satu satuan waktu tertentu. Persamaan untuk kecepatan dapat dinyatakan berikut ini.

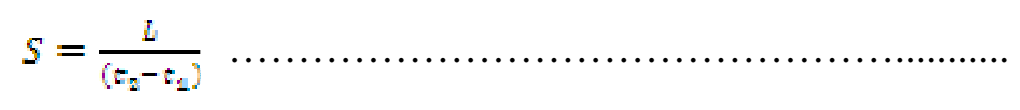

Keterangan:

$$
\begin{aligned}
& \mathrm{S}=\text { Kecepatan }(\mathrm{km} / \mathrm{jam}) \\
& \mathrm{L}=\text { Jarak yang ditempuh oleh sebuah kendaraan }(\mathrm{km}) \\
& \left(t_{2}-t_{1}\right) \quad=\text { waktu untuk melakukan perjalanan (jam). }
\end{aligned}
$$

\subsection{Kepadatan Lalu Lintas}

Menurut Tamin (2008), kepadatan adalah jumlah kendaraan yang berada dalam satu satuan waktu panjang jalan tertentu. Persamaan kepadatan dapat dinyatakan berikut ini.

$$
D=\frac{N}{L}
$$

Keterangan:
$\mathrm{D}=$ Kepadatan $($ kendaraan $/ \mathrm{km})$
$\mathrm{N}$ = Jumlah kendaraan yang berada pada suatu ruas jalan (kendaraan)
$\mathrm{L} \quad=$ Jarak yang ditempuh oleh sebuah kendaraan $(\mathrm{km})$

\subsection{Volume Lalu Lintas}

Menurut Tamin (2008), Volume lalu lintas adalah jumlah kendaraan yang melewati suatu titik tertentu dalam suatu ruas jalan dalam satu satuan waktu tertentu. Persamaan volume lalu lintas dapat dinyatakan berikut ini.

$$
\mathrm{V}=\mathrm{D} \cdot \mathrm{S}
$$

Keterangan:

$$
\begin{aligned}
& \mathrm{V}=\text { Volume lalu lintas (kendaraan } / \mathrm{jam}) \\
& \mathrm{D}=\operatorname{Kepadatan}(\mathrm{kendaraan} / \mathrm{km}) \\
& \mathrm{S}=\operatorname{Kecepatan}(\mathrm{km} / \mathrm{jam})
\end{aligned}
$$




\subsection{Analisis Regresi Linier}

Menurut Nawari (2010), Analisis regresi adalah suatu metode sederhana untuk melakukan investigasi tentang hubungan fungsional diantara beberapa varibel. Persamaannya dapat dinyatakan sebagai berikut.

$$
\begin{aligned}
& \mathrm{Yi}=\mathrm{A}+\mathrm{Bxi} \\
& B=\frac{N \Sigma_{i=1}^{N}(X i Y i)-\Sigma_{i=1}^{N} X i \Sigma_{i=1}^{N} Y i}{N \Sigma_{i=1}^{N}(X i)^{2}-\left(\Sigma_{i=1}^{N} X i\right)^{2}} \\
& \mathrm{~A}=\mathrm{Y}-\mathrm{BX}
\end{aligned}
$$

\subsection{Model Greenshields}

Menurut Tamin (2003), hubungan matematis antara kecepatan-kepadatan (S-D) adalah menoton kebawah yang menyatakan bahwa apabila kepadatan lalu lintas meningkat maka kecepatan akan menurun. Arus lalu lintas akan menjadi 0 (nol) apabila kepadatan sangat tinggi sedemikian rupa sehingga tidak memungkinkan kendaraan untuk bergerak lagi. Pada kondisi kepadatan 0 (nol), kendaraan akan bebas memilih kecepatannya sesuai dengan kondisi ruas jalanyang ada. Apabila kepadatan meningkat dari 0 (nol) maka kecepatan akan menurun sedangkan volume lalu lintas akan meningkat. Greenshields merumuskan bahwa hubungan matematis antara Kecepatan-Kepadatan (S-D) diasumsikan linier. Rangkungan beberapa persamaan yang dihasilkan dari model Greenshields.

Tabel 2.1 Rangkungan persamaan yang dihasilkan dari model Greenshields

\begin{tabular}{|c|l|}
\hline Hubungan & \multicolumn{1}{|c|}{ Persamaan yang Dihasilkan } \\
\hline $\mathrm{S}-\mathrm{D}$ & $S=S_{f f}-\frac{S_{f f}}{D_{j}} \cdot D$ \\
\hline $\mathrm{V}-\mathrm{D}$ & $V=D \cdot S_{f f}-\frac{S_{f f}}{D_{j}} \cdot D^{2}$ \\
\hline $\mathrm{V}-\mathrm{S}$ & $V_{M}=\frac{D_{j}, S-\frac{D_{j f}}{S_{f f}} \cdot S^{2}}{4}$ \\
\hline$V_{M}$ & $S_{M}=\frac{S_{f f}}{2}$ \\
\hline$S_{M}$ & $D_{M}=\frac{D_{j}}{2}$ \\
\hline$D_{M}$ &
\end{tabular}

Keterangan :

$V_{M}=$ kapasitas atau volume maksimum (kendaraan/jam)

$S_{M}=$ kecepatan pada kondisi volume lalu lintas maksimum $(\mathrm{km} / \mathrm{jam})$

$D_{M}=$ kepadatan pada kondisi volume lalu lintas maksimum (kendaraan $/ \mathrm{km}$ )

$D_{j}=$ kepadatan pada kondisi lalu lintas macet total (kendaraan $\left./ \mathrm{km}\right)$

$S_{f f}=$ kecepatan pada kondisi volume lalu lintas sangat rendah $(\mathrm{km} / \mathrm{jam})$ 


\section{Metode Penelitian}

Penelitian ini dilaksanakan pada Jalan Darussalam Kota Lhokseumawe Provinsi Nanggroe Aceh Darussalam. Pengumpulan data dilakukan dengan survey lapangan dan mengumpulkan literatur-literatur yang berhubungan dengan penelitian. Pengumpulan data terdiri dari data primer dan data sekunder. Survey lapangan dilakukan 3 (tiga) hari yaitu hari Senin, Jum'at dan Minggu.

Data primer yang digunakan yaitu data yang diperoleh berdasarkan data survey lapangan, yang terdiri dari data geometrik jalan, volume lalu lintas dan kecepatan kendaraan. Data primer didapat dengan cara observasi atau pengamatan di lokasi penelitian. Pengukuran geometrik jalan meliputi, lebar badan jalan, lebar bahu jalan dan mencatat jumlah lajur dan arah. Menentukan ukuran dengan menggunakan meteran serta alat tulis dan formulir isian untuk melakukan pencatatan. Cara pengamatan volume lalu lintas yaitu dengan menghitung jumlah kendaraan yang melewati titik pengamatan dan mencatat pada formulir yang telah disediakan dengan cara mencatat berdasarkan jenis kendaraan dalam interval lima belas menit. Pencatatan kecepatan kendaraan dilakukan dengan mencatat langsung waktu tempuh yang dibutuhkan kendaraan untuk melintasi masing-masing panjang pias jalan dengan jarak 50 meter.

Sedangkan data sekunder yang digunakan yaitu peta Kota Lhokseumawe sebagai sketsa lokasi. Pengolahan data dilakukan dengan menggunakan persamaan-persamaan yang berhubungan dengan perhitungan kecepatan, volume lalu lintas dan analisis regresi linier.

\section{Hasil Penelitian}

Survey volume lalu lintas dan kecepatan kendaraan dilakukan selama 3 (tiga) hari, yaitu pada hari Senin tanggal 22 Juli 2013, Jum'at tanggal 26 Juli 2013 dan hari Minggu tanggal 28 Juli 2013. Survey dilaksanakan mulai pukul 07.00 WIB sampai dengan pukul 19.00 WIB.

Tabel 4.1 Data Kecepatan dan Volume lalu lintas pada hari Senin

\begin{tabular}{|c|c|c|c|c|c|}
\hline No. & Periode & $\begin{array}{l}\text { Volume (V) } \\
\text { (Smp/Jam) }\end{array}$ & $\begin{array}{c}\text { Kecepatan (S) } \\
\text { (Km/Jam) }\end{array}$ & $\begin{array}{c}\mathbf{D}=\underset{\mathbf{X i}^{2}}{\mathbf{V} / \mathbf{S}}= \\
\end{array}$ & $(\mathbf{X i})^{2}$ \\
\hline 1 & $07.00-07.15$ & 366,20 & 35,00 & 10,46 & 109,47 \\
\hline 2 & $07.15-07.30$ & 546,70 & 34,20 & 15,99 & 255,53 \\
\hline 3 & $07.30-07.45$ & 523,20 & 21,50 & 24,33 & 592,19 \\
\hline 4 & $07.45-08.00$ & 326,10 & 35,80 & 9,11 & 82,97 \\
\hline 5 & $08.00-08.15$ & 402,60 & 40,30 & 9,99 & 99,80 \\
\hline 6 & $08.15-08.30$ & 276,80 & 32,80 & 8,44 & 71,22 \\
\hline 7 & $08.30-08.45$ & 240,30 & 33,86 & 7,10 & 50,37 \\
\hline 8 & $08.45-09.00$ & 390,80 & 23,87 & 16,37 & 268,04 \\
\hline 9 & $09.00-09.15$ & 267,20 & 25,78 & 10,36 & 107,43 \\
\hline 10 & $09.15-09.30$ & 314,60 & 31,00 & 10,15 & 102,99 \\
\hline 11 & $09.30-09.45$ & 262,80 & 18,90 & 13,90 & 193,34 \\
\hline 12 & $09.45-10.00$ & 219,60 & 21,60 & 10,17 & 103,36 \\
\hline 13 & $10.00-10.15$ & 188,80 & 23,80 & 7,93 & 62,93 \\
\hline 14 & $10.15-10.30$ & 255,40 & 35,80 & 7,13 & 50,90 \\
\hline 15 & $10.30-10.45$ & 264,20 & 38,32 & 6,89 & 47,54 \\
\hline
\end{tabular}




\begin{tabular}{|c|c|c|c|c|c|}
\hline 16 & $10.45-11.00$ & 263,60 & 40,12 & 6,57 & 43,17 \\
\hline 17 & $11.00-11.15$ & 296,40 & 39,82 & 7,44 & 55,41 \\
\hline 18 & $11.15-11.30$ & 306,00 & 34,70 & 8,82 & 77,76 \\
\hline 19 & $11.30-11.45$ & 237,00 & 45,30 & 5,23 & 27,37 \\
\hline 20 & $11.45-12.00$ & 214,40 & 48,20 & 4,45 & 19,79 \\
\hline 21 & $12.00-12.15$ & 391,30 & 29,81 & 13,13 & 172,30 \\
\hline 22 & $12.15-12.30$ & 346,60 & 32,86 & 10,55 & 111,26 \\
\hline 23 & $12.30-12.45$ & 272,00 & 38,22 & 7,12 & 50,65 \\
\hline 24 & $12.45-13.00$ & 312,00 & 36,76 & 8,49 & 72,04 \\
\hline 25 & $13.00-13.15$ & 271,00 & 35,42 & 7,65 & 58,54 \\
\hline 26 & $13.15-13.30$ & 257,00 & 32,66 & 7,87 & 61,92 \\
\hline 27 & $13.30-13.45$ & 222,00 & 30,35 & 7,31 & 53,50 \\
\hline 28 & $13.45-14.00$ & 311,60 & 42,10 & 7,40 & 54,78 \\
\hline 29 & $14.00-14.15$ & 268,40 & 27,98 & 9,59 & 92,02 \\
\hline 30 & $14.15-14.30$ & 282,40 & 26,75 & 10,56 & 111,45 \\
\hline 31 & $14.30-14.45$ & 305,60 & 33,40 & 9,15 & 83,72 \\
\hline 32 & $14.45-15.00$ & 262,20 & 32,50 & 8,07 & 65,09 \\
\hline 33 & $15.00-15.15$ & 315,00 & 37,80 & 8,33 & 69,44 \\
\hline 34 & $15.15-15.30$ & 262,80 & 31,23 & 8,41 & 70,81 \\
\hline 35 & $15.30-15.45$ & 249,80 & 40,20 & 6,21 & 38,61 \\
\hline 36 & $15.45-16.00$ & 257,40 & 36,80 & 6,99 & 48,92 \\
\hline 37 & $16.00-16.15$ & 292,20 & 32,90 & 8,88 & 78,88 \\
\hline 38 & $16.15-16.30$ & 369,40 & 36,70 & 10,07 & 101,31 \\
\hline 39 & $16.30-16.45$ & 275,20 & 32,90 & 8,36 & 69,97 \\
\hline 40 & $16.45-17.00$ & 333,00 & 40,23 & 8,28 & 68,52 \\
\hline 41 & $17.00-17.15$ & 363,20 & 30,12 & 12,06 & 145,41 \\
\hline 42 & $17.15-17.30$ & 307,00 & 21,54 & 14,25 & 203,14 \\
\hline 43 & $17.30-17.45$ & 283,40 & 26,80 & 10,57 & 111,82 \\
\hline 44 & $17.45-18.00$ & 217,20 & 35,20 & 6,17 & 38,07 \\
\hline 45 & $18.00-18.15$ & 685,20 & 26,30 & 26,05 & 678,77 \\
\hline 46 & $18.15-18.30$ & 263,20 & 29,43 & 8,94 & 79,98 \\
\hline 47 & $18.30-18.45$ & 335,20 & 30,21 & 11,10 & 123,11 \\
\hline \multirow[t]{3}{*}{48} & $18.45-19.00$ & 328,40 & 31,56 & 10,41 & 108,28 \\
\hline & $\Sigma$ & $14.802,40$ & $1.579,40$ & 472,83 & $5.443,88$ \\
\hline & Rata-rata & & 32,90 & $\mathbf{9 , 8 5}$ & \\
\hline
\end{tabular}

Tabel 4.2 Data Kecepatan dan Volume lalu lintas pada hari Jum'at

\begin{tabular}{|c|c|c|c|c|c|}
\hline No. & Periode & $\begin{array}{c}\text { Volume (V) } \\
(\mathbf{S m p} / \mathbf{J a m})\end{array}$ & $\begin{array}{c}\text { Kecepatan }(\mathbf{S}) \\
(\mathbf{K m} / \mathbf{J a m})\end{array}$ & $\begin{array}{c}\mathbf{D}=\mathbf{V} / \mathbf{S}= \\
\mathbf{X i}^{\mathbf{2}}\end{array}$ & $\mathbf{( \mathbf { X i }}^{\mathbf{2}}$ \\
\hline 1 & $07.00-07.15$ & 268,80 & 42,80 & 6,28 & 39,44 \\
\hline 2 & $07.15-07.30$ & 533,20 & 34,92 & 15,27 & 233,15 \\
\hline 3 & $07.30-07.45$ & 376,60 & 30,33 & 12,42 & 154,18 \\
\hline 4 & $07.45-08.00$ & 449,90 & 41,20 & 10,92 & 119,24 \\
\hline 5 & $08.00-08.15$ & 340,40 & 30,38 & 11,20 & 125,55 \\
\hline 6 & $08.15-08.30$ & 254,10 & 31,90 & 7,97 & 63,45 \\
\hline 7 & $08.30-08.45$ & 269,40 & 29,45 & 9,15 & 83,68 \\
\hline 8 & $08.45-09.00$ & 262,20 & 27,68 & 9,47 & 89,73 \\
\hline 9 & $09.00-09.15$ & 230,60 & 20,34 & 11,34 & 128,53 \\
\hline 10 & $09.15-09.30$ & 203,20 & 46,30 & 4,22 & 17,77 \\
\hline 11 & $09.30-09.45$ & 259,40 & 34,67 & 7,48 & 55,98 \\
\hline 12 & $09.45-10.00$ & 278,40 & 21,64 & 12,87 & 165,51 \\
\hline
\end{tabular}




\begin{tabular}{|c|c|c|c|c|c|}
\hline 13 & $10.00-10.15$ & 292,00 & 22,78 & 12,82 & 164,31 \\
\hline 14 & $10.15-10.30$ & 262,60 & 33,74 & 7,78 & 60,58 \\
\hline 15 & $10.30-10.45$ & 240,20 & 20,10 & 11,95 & 142,81 \\
\hline 16 & $10.45-11.00$ & 270,80 & 29,33 & 9,23 & 85,25 \\
\hline 17 & $11.00-11.15$ & 267,80 & 30,22 & 8,86 & 78,53 \\
\hline 18 & $11.15-11.30$ & 264,00 & 34,72 & 7,60 & 57,82 \\
\hline 19 & $11.30-11.45$ & 260,80 & 36,80 & 7,09 & 50,22 \\
\hline 20 & $11.45-12.00$ & 255,40 & 39,20 & 6,52 & 42,45 \\
\hline 21 & $12.00-12.15$ & 309,20 & 37,12 & 8,33 & 69,38 \\
\hline 22 & $12.15-12.30$ & 407,00 & 28,34 & 14,36 & 206,25 \\
\hline 23 & $12.30-12.45$ & 393,60 & 39,20 & 10,04 & 100,82 \\
\hline 24 & $12.45-13.00$ & - & - & - & - \\
\hline 25 & $13.00-13.15$ & - & - & - & - \\
\hline 26 & $13.15-13.30$ & - & - & - & - \\
\hline 27 & $13.30-13.45$ & 350,00 & 40,00 & 8,75 & 76,56 \\
\hline 28 & $13.45-14.00$ & 402,20 & 38,20 & 10,53 & 110,86 \\
\hline 29 & $14.00-14.15$ & 337,20 & 27,90 & 12,09 & 146,07 \\
\hline 30 & $14.15-14.30$ & 281,00 & 38,20 & 7,36 & 54,11 \\
\hline 31 & $14.30-14.45$ & 280,80 & 23,70 & 11,85 & 140,38 \\
\hline 32 & $14.45-15.00$ & 248,40 & 28,53 & 8,71 & 75,81 \\
\hline 33 & $15.00-15.15$ & 271,00 & 29,38 & 9,22 & 85,08 \\
\hline 34 & $15.15-15.30$ & 255,80 & 33,23 & 7,70 & 59,26 \\
\hline 35 & $15.30-15.45$ & 272,80 & 38,10 & 7,16 & 51,27 \\
\hline 36 & $15.45-16.00$ & 246,80 & 27,15 & 9,09 & 82,63 \\
\hline 37 & $16.00-16.15$ & 233,20 & 28,24 & 8,26 & 68,19 \\
\hline 38 & $16.15-16.30$ & 270,40 & 33,78 & 8,00 & 64,08 \\
\hline 39 & $16.30-16.45$ & 290,60 & 37,12 & 7,83 & 61,29 \\
\hline 40 & $16.45-17.00$ & 275,00 & 40,23 & 6,84 & 46,73 \\
\hline 41 & $17.00-17.15$ & 331,20 & 27,50 & 12,04 & 145,05 \\
\hline 42 & $17.15-17.30$ & 313,30 & 34,98 & 8,96 & 80,22 \\
\hline 43 & $17.30-17.45$ & 280,20 & 23,80 & 11,77 & 138,61 \\
\hline 44 & $17.45-18.00$ & 264,90 & 36,70 & 7,22 & 52,10 \\
\hline 45 & $18.00-18.15$ & 245,00 & 29,80 & 8,22 & 67,59 \\
\hline 46 & $18.15-18.30$ & 283,60 & 33,11 & 9,09 & 82,57 \\
\hline 47 & $18.30-18.45$ & 252,20 & 23,85 & 10,57 & 111,82 \\
\hline 48 & $18.45-19.00$ & 254,80 & 41,30 & 6,17 & 38,06 \\
\hline & $\mathbf{2}$ & $\mathbf{1 3 . 1 9 0 , 0 0}$ & $\mathbf{1 . 4 5 7 , 9 6}$ & $\mathbf{4 2 0 , 5 8}$ & $\mathbf{4 . 1 7 2 , 9 4}$ \\
\hline & $\mathbf{R a t a}-\mathbf{r a t a}$ & & $\mathbf{3 0 , 3 7}$ & $\mathbf{8 , 7 6}$ & \\
\hline & & & & & \\
\hline
\end{tabular}

Tabel 4.3 Data Kecepatan dan Volume lalu lintas pada hari Minggu

\begin{tabular}{|c|c|c|c|c|c|}
\hline No. & Periode & $\begin{array}{c}\text { Volume (V) } \\
(\mathbf{S m p / J a m})\end{array}$ & $\begin{array}{c}\text { Kecepatan }(\mathbf{S}) \\
(\mathbf{K m} / \mathbf{J a m})\end{array}$ & $\begin{array}{c}\mathbf{D}=\mathbf{V} / \mathbf{S}= \\
\mathbf{X i}^{\mathbf{2}}\end{array}$ & $\mathbf{( \mathbf { X i }}^{\mathbf{2}}$ \\
\hline 1 & $07.00-07.15$ & 25,00 & 54,30 & 0,46 & 0,21 \\
\hline 2 & $07.15-07.30$ & 33,60 & 40,30 & 0,83 & 0,70 \\
\hline 3 & $07.30-07.45$ & 45,20 & 39,60 & 1,14 & 1,30 \\
\hline 4 & $07.45-08.00$ & 102,00 & 41,20 & 2,48 & 6,13 \\
\hline 5 & $08.00-08.15$ & 133,50 & 47,80 & 2,79 & 7,80 \\
\hline 6 & $08.15-08.30$ & 92,00 & 50,20 & 1,83 & 3,36 \\
\hline 7 & $08.30-08.45$ & 82,60 & 55,60 & 1,49 & 2,21 \\
\hline 8 & $08.45-09.00$ & 102,00 & 45,70 & 2,23 & 4,98 \\
\hline
\end{tabular}




\begin{tabular}{|c|c|c|c|c|c|}
\hline 9 & $09.00-09.15$ & 56,40 & 40,30 & 1,40 & 1,96 \\
\hline 10 & $09.15-09.30$ & 62,20 & 39,60 & 1,57 & 2,47 \\
\hline 11 & $09.30-09.45$ & 60,00 & 41,89 & 1,43 & 2,05 \\
\hline 12 & $09.45-10.00$ & 62,60 & 34,76 & 1,80 & 3,24 \\
\hline 13 & $10.00-10.15$ & 75,20 & 40,12 & 1,87 & 3,51 \\
\hline 14 & $10.15-10.30$ & 50,40 & 37,94 & 1,33 & 1,76 \\
\hline 15 & $10.30-10.45$ & 70,80 & 43,80 & 1,62 & 2,61 \\
\hline 16 & $10.45-11.00$ & 120,40 & 47,20 & 2,55 & 6,51 \\
\hline 17 & $11.00-11.15$ & 103,60 & 46,12 & 2,25 & 5,05 \\
\hline 18 & $11.15-11.30$ & 114,40 & 36,88 & 3,10 & 9,62 \\
\hline 19 & $11.30-11.45$ & 80,60 & 54,69 & 1,47 & 2,17 \\
\hline 20 & $11.45-12.00$ & 89,00 & 52,18 & 1,71 & 2,91 \\
\hline 21 & $12.00-12.15$ & 83,00 & 55,82 & 1,49 & 2,21 \\
\hline 22 & $12.15-12.30$ & 76,60 & 54,32 & 1,41 & 1,99 \\
\hline 23 & $12.30-12.45$ & 80,60 & 34,67 & 2,32 & 5,40 \\
\hline 24 & $12.45-13.00$ & 74,80 & 38,81 & 1,93 & 3,71 \\
\hline 25 & $13.00-13.15$ & 65,00 & 45,30 & 1,43 & 2,06 \\
\hline 26 & $13.15-13.30$ & 47,20 & 50,40 & 0,94 & 0,88 \\
\hline 27 & $13.30-13.45$ & 48,80 & 51,90 & 0,94 & 0,88 \\
\hline 28 & $13.45-14.00$ & 64,20 & 45,20 & 1,42 & 2,02 \\
\hline 29 & $14.00-14.15$ & 69,40 & 42,20 & 1,64 & 2,70 \\
\hline 30 & $14.15-14.30$ & 96,00 & 38,34 & 2,50 & 6,27 \\
\hline 31 & $14.30-14.45$ & 88,00 & 41,10 & 2,14 & 4,58 \\
\hline 32 & $14.45-15.00$ & 107,40 & 40,23 & 2,67 & 7,13 \\
\hline 33 & $15.00-15.15$ & 129,60 & 32,10 & 4,04 & 16,30 \\
\hline 34 & $15.15-15.30$ & 154,40 & 37,20 & 4,15 & 17,23 \\
\hline 35 & $15.30-15.45$ & 150,20 & 36,90 & 4,07 & 16,57 \\
\hline 36 & $15.45-16.00$ & 197,20 & 38,76 & 5,09 & 25,88 \\
\hline 37 & $16.00-16.15$ & 199,20 & 31,02 & 6,42 & 41,24 \\
\hline 38 & $16.15-16.30$ & 343,40 & 33,71 & 10,19 & 103,77 \\
\hline 39 & $16.30-16.45$ & 375,40 & 33,80 & 11,11 & 123,35 \\
\hline 40 & $16.45-17.00$ & 331,40 & 31,21 & 10,62 & 112,75 \\
\hline 41 & $17.00-17.15$ & 369,20 & 26,34 & 14,02 & 196,47 \\
\hline 42 & $17.15-17.30$ & 372,70 & 27,80 & 13,41 & 179,73 \\
\hline 43 & $17.30-17.45$ & 393,10 & 32,90 & 11,95 & 142,76 \\
\hline 44 & $17.45-18.00$ & 567,00 & 28,35 & 20,00 & 400,00 \\
\hline 45 & $18.00-18.15$ & 463,10 & 32,90 & 14,08 & 198,13 \\
\hline 46 & $18.15-18.30$ & 458,00 & 36,13 & 12,68 & 160,69 \\
\hline 47 & $18.30-18.45$ & 673,00 & 28,54 & 23,58 & 556,06 \\
\hline 48 & $18.45-19.00$ & 560,00 & 31,71 & 17,66 & 311,88 \\
\hline & $\mathbf{2}$ & $\mathbf{8 . 1 9 9 , 4 0}$ & $\mathbf{1 . 9 4 7 , 8 4}$ & $\mathbf{2 3 9 , 2 4}$ & $\mathbf{2 . 7 1 3 , 2 2}$ \\
\hline & $\mathbf{R a t a}-\mathbf{r a t a}$ & & $\mathbf{4 0 , 5 8}$ & $\mathbf{4 , 9 8}$ & \\
\hline & & & & & \\
\hline
\end{tabular}

\subsection{Volume Lalu Lintas}

Jumlah volume lalu lintas pada hari Senin tanggal 22 Juli 2013 diperoleh sebesar 14.802,40 Smp/Jam, pada hari Jum'at tanggal 26 Juli 2013 diperoleh sebesar 13.190 Smp/Jam dan pada hari Minggu tanggal 28 Juli 2013 diperoleh sebesar 8.199,40 Smp/Jam. Volume paling tinggi pada hari Senin terjadi mulai pukul 18.00 WIB sampai dengan pukul 18.15 WIB yaitu sebesar 685,20 smp/jam. Sedangkan volume paling tinggi pada hari Jum'at terjadi mulai pukul 07.15 WIB 
sampai dengan 07.30 WIB yaitu sebesar 533,20 smp/jam. Dan volume paling tinggi pada hari Minggu terjadi mulai pukul 18.30 WIB sampai dengan pukul 18.45 WIB.

\subsection{Kecepatan Kendaraan}

Kecepatan rata-rata kendaraan pada hari Senin tanggal 23 September 2013 diperoleh sebesar 32,90 Km/Jam, pada hari Jum'at tanggal 27 September 2013 diperoleh sebesar 30,37 Km/Jam dan pada hari Minggu tanggal 29 September 2013 diperoleh sebesar 40,58 Km/Jam. Kecepatan rata-rata paling tinggi pada hari Senin terjadi mulai pukul 11.45 WIB sampai dengan 12.00 WIB yaitu sebesar 48,20 km/jam, sedangkan kecepatan rata-rata paling tinggi pada hari Jum'at terjadi mulai pukul 09.15 WIB sampai dengan pukul 09.30 WIB yaitu sebesar 46,30 $\mathrm{km} / \mathrm{jam}$. Dan kecepatan rata-rata paling tinggi pada hari Minggu terjadi mulai pukul 12.00 WIB sampai dengan pukul 12.15 WIB yaitu sebesar 55,82 km/jam.

\subsection{Hubungan Matematis Hari Senin}

Hubungan matematis antara kecepatan, kepadatan dan volume lalu lintas untuk hari Senin, seperti berikut.

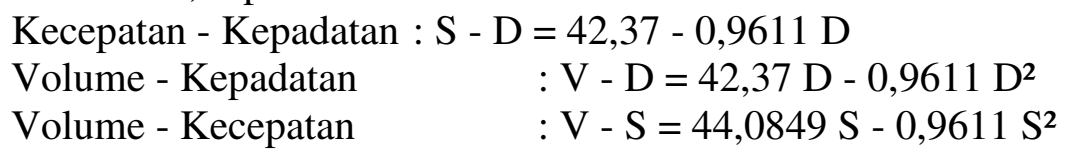

\subsection{Hubungan Matematis Hari Jum'at}

Hubungan matematis antara kecepatan, kepadatan dan volume lalu lintas untuk hari Jum'at, seperti berikut.

$$
\begin{aligned}
& \text { Kecepatan - Kepadatan : S - D = 22,915 + 0,8513 D } \\
& \text { Volume - Kepadatan } \quad: \text { V - D }=22,915 \text { D - 0,8513 D } \\
& \text { Volume - Kecepatan } \quad: \mathrm{V}-\mathrm{S}=-26,9177 \mathrm{~S}+1,1747 \mathrm{~S}^{2}
\end{aligned}
$$

\subsection{Hubungan Matematis Hari Minggu}

Hubungan matematis antara kecepatan, kepadatan dan volume lalu lintas untuk hari Minggu, seperti berikut.

Kecepatan - Kepadatan : S - D = 45,5254 - 0,9922 D

Volume - Kepadatan $\quad: \mathrm{V}-\mathrm{D}=45,5254 \mathrm{D}-0,9922 \mathrm{D}^{2}$

Volume - Kecepatan $\quad: \mathrm{V}-\mathrm{S}=45,8821 \mathrm{~S}-1,0078 \mathrm{~S}^{2}$

\section{Kesimpulan}

Berdasarkan dari hasil penelitian maka dapat diambil kesimpulan sebagai berikut :

1. Volume lalu lintas pada hari Senin diperoleh sebesar $14.802,40 \mathrm{smp} / \mathrm{jam}$, pada hari Jum'at sebesar $13.190 \mathrm{smp} / \mathrm{jam}$ dan pada hari Minggu sebesar 8.199,40 smp/jam. Ini berarti bahwa volume lalu lintas untuk hari Senin lebih besar daripada hari Jum'at atau hari Minggu.

2. Kecepatan Kendaraan pada hari Senin diperoleh rata-rata sebesar 32,90 $\mathrm{km} / \mathrm{jam}$, sedangkan pada Jum'at diperoleh rata-rata sebesar 30,37 km/jam dan pada hari Minggu diperoleh rata-rata sebesar 40,58 km/jam. Ini berarti bahwa kecepatan kendaraan pada hari Minggu lebih cepat daripada hari Senin maupun hari Jum'at. 
3. Bentuk matematis hubungan antara Kecepatan dan Kepadatan untuk hari Senin adalah $\mathrm{S}-\mathrm{D}=42,37-0,9611 \mathrm{D}$, sedangkan untuk hari Jum'at adalah $\mathrm{S}-\mathrm{D}=$ $22,915+0,8513$ D dan untuk hari Minggu adalah $S-D=45,5254-0,9922$ D.

4. Bentuk matematis hubungan antara Volume dan Kepadatan untuk hari Senin adalah V - D = 42,37 D - 0,9611 D², sedangkan pada hari Jum'at adalah V - D $=22,915 \mathrm{D}-0,8513 \mathrm{D}^{2}$, dan untuk hari Minggu adalah $\mathrm{V}-\mathrm{D}=45,5254 \mathrm{D}-$ $0,9922 \mathrm{D}^{2}$.

5. Bentuk matematis hubungan antara Volume dan Kecepatan untuk hari Senin adalah $\mathrm{V}-\mathrm{S}=44,0849 \mathrm{~S}-0,9611 \mathrm{~S}^{2}$, sedangkan untuk hari Jum'at adalah V - S $=-26,9177 \mathrm{~S}+1,1747 \mathrm{~S}^{2}$, dan untuk hari Minggu adalah $\mathrm{V}-\mathrm{S}=45,8821 \mathrm{~S}-$ $1,0078 \mathrm{~S}^{2}$.

\section{Daftar Kepustakaan}

1. Tamin, O, Z, 2008, Perencanaan dan Pemodelan Transportasi, Institut Teknologi Bandung, Bandung.

2. Nawari, 2010, Analisis Regresi dengan MS Excel 2007 dan SPSS 17, PT. Elex Media Komputindo, Jakarta. 